\title{
Susceptibility of diploid, tetraploid and hexaploid wheat species to Zymoseptoria tritici and Blumeria graminis infections
}

\author{
Podatność diploidalnych, tetraploidalnych i heksaploidalnych gatunków \\ pszenicy na porażenie przez Zymoseptoria tritici i Blumeria graminis
}

\author{
Adrian Duba, Urszula Wachowska*
}

\begin{abstract}
Summary
Blumeria graminis and Zymoseptoria tritici are dangerous pathogens of cereals causing powdery mildew and Septoria tritici blotch (STB) of wheat, respectively. A two-year field-plot experiment was conducted to determine the susceptibility of the diploid species Triticum monococcum ssp. monococcum, tetraploid species T. turgidum ssp. dicoccum and T. turgidum ssp. polonicum, and hexaploid species $T$. aestivum ssp. spelta and T. aestivum ssp. aestivum to infections caused by $B$. graminis and $Z$. tritici. In a greenhouse experiment, the analyzed wheat species were inoculated with a spore suspension of $Z$. tritici. Common wheat was infected the most by the examined pathogens. Tetraploid wheat species were relatively susceptible to STB, whereas the symptoms of powdery mildew were observed only in the field experiments in 2016. The diploid species T. monococcum ssp. monococcum was not infected by either of the pathogens under field conditions, but it was infected by $Z$. tritici after inoculation in the greenhouse conditions.
\end{abstract}

Key words: Triticum turgidum; Triticum aestivum; Triticum monococcum; Septoria leaf blotch; powdery mildew

\section{Streszczenie}

Gatunki Zymoseptoria tritici i Blumeria graminis to groźne patogeny zbóż powodujące septoriozę paskowaną liści oraz mączniaka prawdziwego zbóż i traw. W dwuletnich badaniach poletkowych oceniano wrażliwość diplodalnego gatunku Triticum monococcum ssp. monococcum, tetraploidalnych $T$. turgidum ssp. dicoccum i $T$. turgidum ssp. polonicum oraz heksaploidalnych gatunków $T$. aestivum ssp. spelta i T. aestivum ssp. aestivum na porażenie przez B. graminis i Z. tritici. W szklarni pszenice inokulowano zawiesiną zarodników Z. tritici. Pszenica zwyczajna była najsilniej porażana przez badane patogeny. Gatunki tetraploidalne wykazywały dość dużą podatność na porażenie przez Z. tritici, objawy mączniaka prawdziwego obserwowano na liściach tych gatunków w warunkach polowych tylko w pierwszym roku badań. Diploidalny gatunek $T$. monococcum ssp. monococcum nie był porażany przez żaden z omawianych patogenów w warunkach naturalnych, natomiast uległ porażeniu przez Z. tritici po inokulacji roślin w szklarni.

Słowa kluczowe: Triticum turgidum; Triticum aestivum; Triticum monococcum; septorioza paskowana liści; mączniak prawdziwy zbóż i traw

Uniwersytet Warmińsko-Mazurski w Olsztynie

Katedra Entomologii, Fitopatologii i Diagnostyki Molekularnej

Prawocheńskiego 17, 10-720 Olsztyn

*corresponding author: urszula.wachowska@uwm.edu.p 


\section{Wstęp / Introduction}

Grzyb Zymoseptoria tritici (Desm.) Quaedvlieg \& Crous [synonim: Septoria tritici Desm., teleomorfa: Mycosphaerella graminicola (Fuckel) Schroeter] to patogen powodujący septoriozę paskowaną liści. Jest to jedna z groźniejszych chorób pszenicy w Polsce (Mirzwa-Mróz i wsp. 2005; Wachowska i wsp. 2018). Grzyb Z. tritici jest hemibiotrofem z długą fazą biotroficzną bez objawów chorobowych, po której następuje faza nekrotroficzna (Somai-Jemmali i wsp. 2017). W tej ostatniej fazie tkanka liści zamiera, z czasem tworzą się na niej piknidia (Shetty i wsp. 2009). Proces infekcji Z. tritici rozpoczynają kiełkujące askospory i piknidiospory na powierzchni liścia. Z. tritici wnika do rośliny najczęściej przez aparaty szparkowe (Jing i wsp. 2008; Shetty i wsp. 2009), rzadziej bezpośrednio przez epidermę (Somai-Jemmali i wsp. 2017). Patogen rozprzestrzenia się wyłącznie międzykomórkowo, nie tworzy ssawek lub innych specjalistycznych struktur (Somai-Jemmali i wsp. 2017). Rozwój epidemii septoriozy paskowanej liści jest ściśle związany z przebiegiem warunków pogodowych, a tempo rozwoju objawów choroby uzależnione jest od podatności rośliny żywicielskiej (Mirzwa-Mróz i Zamorski 2002).

Patogen Blumeria graminis (DC.) E.O. Speer f. sp. tritici Em. Marchali jest sprawcą mączniaka prawdziwego zbóż i traw. Grzyb ten jest obligatoryjnym biotrofem, tworzącym zróżnicowane formy specjalne (f. sp.), które porażają różnych żywicieli. Patogen B. graminis f. sp. tritici infekuje wyłącznie komórki epidermy i kolonizuje powierzchnię liści żywiciela (Esmail i Draz 2017). W badaniach Esmail i Draz (2017) po
5 dniach od inokulacji patogen tworzył rozległy nalot strzępek z licznymi ssawkami wrastającymi do komórek epidermy i bulwiaste konidiofory z konidiami (oidiami). Z czasem na nalocie tworzą się chasmotecja wypełnione zarodnikami workowymi (Mirzwa-Mróz i Zamorski 2002).

Diplodalny gatunek Triticum monococcum ssp. monococcum, tetraploidalne T. turgidum ssp. dicoccum i T. turgidum ssp. polonicum oraz heksaploidalny T. aestivum ssp. spelta mogą stanowić potencjalne źródła genów odporności dla T. aestivum ssp. aestivum. Podatność wymienionych gatunków pszenic, uprawianych $\mathrm{w}$ Polsce na niewielkim areale, na porażenie przez patogeny jest słabo poznana (Wiwart i wsp. 2016).

Celem badań była ocena wrażliwości jarych form pszenicy o różnym stopniu ploidalności na porażenie przez patogeny $B$. graminis i $Z$. tritici oraz prześledzenie rozwoju chorób przez nie powodowanych.

\section{Materiały i metody / Materials and methods}

\section{Materiał roślinny}

Materiał do badań stanowiło siedem linii i odmian pszenic o różnym stopniu ploidalności: diplodalny gatunek T. monococcum ssp. monococcum 405, tetraploidalne T. turgidum ssp. dicoccum 475 i T. turgidum ssp. polonicum 618 oraz heksaploidalne T. aestivum ssp. spelta odmiana Wirtas oraz T. aestivum ssp. spelta 307, a także linia T. aestivum ssp. aestivum 307 i odmiana Sumai 3 (tab. 1). Ziarno pochodziło z rozmnożeń akcesji uzyskanych z Leibniz Institute of Plant Genetics and Crop Plant Research IPK, Gatersleben (Niemcy) i z National Plant Germplasm System (USA).

Tabela 1. Pochodzenie gatunków Triticum użytych w doświadczeniach

Table 1. Origin of Triticum species genotypes used in the trials

\begin{tabular}{|c|c|c|}
\hline $\begin{array}{l}\text { Gatunek Triticum / Numer taksonu lub odmiana } \\
\text { Species Triticum / Taxon number or cultivar }\end{array}$ & $\begin{array}{l}\text { Ploidalność } \\
\text { Ploidy }\end{array}$ & $\begin{array}{l}\text { Pochodzenie } \\
\text { Origin }\end{array}$ \\
\hline $\begin{array}{l}\text { Pszenica samopsza - Einkorn wheat } \\
\text { (T. monococcum ssp. monococcum) } 405\end{array}$ & diploid & TRI579/Niemcy - Germany \\
\hline $\begin{array}{l}\text { Pszenica płaskurka - Emmer wheat } \\
\text { (T. turgidum ssp. dicoccum) } 475\end{array}$ & tetraploid & TRI9574/Niemcy - Germany \\
\hline $\begin{array}{l}\text { Pszenica polska - Polish wheat } \\
\text { (T. turgidum ssp. polonicum) } 618\end{array}$ & tetraploid & TRI3550/Niemcy - Germany \\
\hline $\begin{array}{l}\text { Pszenica orkisz - Spelt wheat } \\
\text { (T. aestivum ssp. spelta) } 157\end{array}$ & heksaploid - hexaploid & PI168679/USA \\
\hline $\begin{array}{l}\text { Pszenica orkisz - Spelt wheat } \\
\text { (T. aestivum ssp. spelta) } \\
\text { odmiana - cultivar Wirtas }\end{array}$ & heksaploid - hexaploid & UWM \\
\hline $\begin{array}{l}\text { Pszenica zwyczajna - Bread wheat } \\
\text { (T. aestivum ssp. aestivum) } 307\end{array}$ & heksaploid - hexaploid & PI387457/USA \\
\hline $\begin{array}{l}\text { Pszenica zwyczajna - Bread wheat } \\
\text { (T. aestivum ssp. aestivum) } \\
\text { odmiana - cultivar Sumai } 3\end{array}$ & heksaploid - hexaploid & $\begin{array}{c}\text { UWM } \\
\text { (rozmnożenie własne } \\
\text { - own reproduction) }\end{array}$ \\
\hline
\end{tabular}

UWM - Uniwersytet Warmińsko-Mazurski w Olsztynie - University of Warmia and Mazury in Olsztyn 
Dwie odmiany jare włączone do badań, polską odmianę orkiszu Wirtas zarejestrowaną w roku 2015 (COBORU 2015) i odmianę pszenicy zwyczajnej Sumai 3, rozmnożono w Bałcynach, w Polsce północno-wschodniej.

\section{Badania polowe}

Ocenę wrażliwości pszenic na porażenie przez patogeny $Z$. tritici i $B$. graminis f. sp. tritici monitorowano w doświadczeniu poletkowym zlokalizowanym w Tomaszkowie koło Olsztyna. Badania prowadzono w latach 2016 i 2017. W roku 2016 od kwietnia do lipca było cieplej (przeciętne temperatury $\mathrm{w}$ kwietniu $7,4^{\circ} \mathrm{C}$, maju $13,6^{\circ} \mathrm{C}$, czerwcu $17,1^{\circ} \mathrm{C}$, lipcu $18,1^{\circ} \mathrm{C}$ ) niż w roku 2017 (w kwietniu $5,7^{\circ} \mathrm{C}$, maju $12,1^{\circ} \mathrm{C}$, czerwcu $15,7^{\circ} \mathrm{C}$, lipcu $16,7^{\circ} \mathrm{C}$ ). W pierwszym roku badań od maja do lipca odnotowano też na ogół większą ilość opadów (w maju 56,9 mm, czerwcu 69,3 mm, lipcu 130,4 mm) niż w drugim roku (w maju 25,1 mm, czerwcu 74,5 mm, lipcu 107,6 mm). Jednak opady w kwietniu w roku 2017 (59,1 mm) były zdecydowanie bardziej obfite niż w roku 2016 (28,8 mm). Pszenice jare wysiewano na poletkach o powierzchni $1 \mathrm{~m}^{2}$. Nawożenie azotowe, potasowe i fosforowe zastosowano na całej powierzchni doświadczenia. Wynosiło ono w przeliczeniu na 1 hektar: $\mathrm{P}_{2} \mathrm{O}_{5}-60 \mathrm{~kg}$ (superfosfat Fosdar ${ }^{\mathrm{TM}}$, Gdańskie Zakłady Nawozów Fosforowych Fosfory Sp. z o.o.), N - 100 kg (saletra amonowa 34\%, Grupa Azoty, Puławy), $\mathrm{K}_{2} \mathrm{O}-60 \mathrm{~kg}$ (sól potasowa $60 \%$, Luvena, Luboń). Nasilenie porażenia liści flagowych pszenic określano w fazie dojrzałości woskowej ziarna (BBCH 83) (Meier 2003). Łącznie oceniano 100 losowo wybranych liści z każdej linii/odmiany. Ocenę porażenia roślin wykonano na podstawie skali opracowanej przez Europejską i Śródziemnomorską Organizację Ochrony Roślin - Bulletin EPPO (1998), odnotowując średni procent porażenia liści. Za wrażliwe uznano linie/odmiany o dużej podatności na porażenie - wówczas, gdy ponad $30 \%$ powierzchni liści wykazywało zmiany chorobowe. Za odporne/mało podatne uznano rośliny o małej podatności na porażenie - nasilenie objawów chorób nie przekraczało 5\% powierzchni liści.

\section{Badania szklarniowe}

W roku 2016 ziarno pszenicy zwyczajnej i kłoski form niewymłacalnych wysiewano do plastikowych doniczek o średnicy $22 \mathrm{~cm}$ wypełnionych glebą ogrodniczą. Do doniczek wysiewano po 20 ziaren/kłosków na głębokość $1 \mathrm{~cm}$. Doświadczenie założono w trzech powtórzeniach. Rosnące rośliny regularnie podlewano i nawożono w okresie strzelania w źdźbło (BBCH 31, Polifoska ${ }^{\circledR}$ 6, Grupa Azoty, Puławy, 12 gram/donicę). W fazie pełni kłoszenia (BBCH 55) liście pszenic inokulowano wodną zawiesiną zarodników Z. tritici o gęstości $10^{-6} / \mathrm{ml} \mathrm{z}$ dodatkiem $0,01 \%$ Tween-20 (Sigma-Aldrich, Polska). Wybrany izolat Z. tritici Zt5 pochodził z kolekcji Katedry Entomologii, Fitopatologii i Diagnostyki Molekularnej, uzyskano go w roku 2014 z liści pszenicy ozimej odmiany Bogatka. Izolat przechowywany był $\mathrm{w}$ temperaturze $-80^{\circ} \mathrm{C}$. Hodowano go na podłożu glukozowo-ziemniaczanym w temperaturze $24^{\circ} \mathrm{C}$ przez okres 10 dni. Sekwencję amplikonu izolatu Z. tritici Zt5, uzyskaną za pomocą starterów ITS4 i ITS5 (White i wsp. 1990), umieszczono w GenBank BLAST (NCBI 2016) pod numerem akcesyjnym KX272953. Koncentrację zarodników określono w komorze Thoma w mikroskopie Nikon Eclipse E 200 (Japonia). Inokulację wykonano opryskując liście flagowe wodną zawiesiną zarodników opryskiwaczem ręcznym (Marolex, Titan, Polska). Inokulowane rośliny przykryto plastikowymi torebkami na 48 godzin. Rozwój objawów chorobowych monitorowano co cztery dni. Ocenę porażenia roślin wykonano po 30 dniach.

\section{Analiza statystyczna}

Analizę wariancji wykonano za pomocą programu Statistica 12 (ANOVA). Istotność różnic między średnimi oszacowano testem Newmana-Keulsa $(p<0,01)$.

\section{Wyniki i dyskusja / Results and discussion}

W latach 2016-2017 w warunkach naturalnych infekcji nasilenie septoriozy paskowanej liści na liściach flagowych siedmiu genotypów pszenic o różnym stopniu ploidalności było zróżnicowane (tab. 2). W roku 2017 przebieg warunków pogodowych był bardziej korzystny dla rozwoju septoriozy paskowanej liści, niż w roku 2016. Rośliny heksaploidalnej pszenicy T. aestivum odmiany Sumai 3 i linii 307 wykazywały typowe objawy choroby z nekrotycznymi plamami i piknidiami. Nasilenie tych objawów w roku 2017 wynosiło kolejno 7,78 i 90,01\% powierzchni ocenianych liści flagowych (tab. 2). We wcześniejszych badaniach objawy septoriozy paskowanej liści występowały w różnym nasileniu w zależności od genotypu pszenicy zwyczajnej, a ich nasilenie uzależnione było także od przebiegu warunków pogodowych (Mirzwa-Mróz i Zamorski 2002). W Polsce stadium doskonałe w postaci pseudotecjów wypełnionych zarodnikami workowymi na obumierających liściach obserwowano już w lipcu (Mirzwa-Mróz i wsp. 2005).

W prezentowanych badaniach na liściach heksaploidalnej pszenicy orkisz odmiany Wirtas i linii 157, wysianych na poletkach, obserwowano nekrotyczne wydłużone plamy bez obecności piknidiów (tab. 2). W szklarni po inokulacji liści izolatem $Z$. tritici pszenica orkisz nie wykazywała zmian chorobowych (tab. 3). W badaniach Simon i wsp. (2010) prowadzonych w szklarni inokulowano 87 linii T. aestivum spp. spelta w dwóch terminach: w fazie siewki i fazie dojrzewania ziarna. Ponad 80\% testowanych linii wykazywało nekrozy na liściach flagowych. Cytowani autorzy obserwowali piknidia na liściach siewek, wyłącznie na roślinach pszenicy orkisz inokulowanych w fazie siewki. 
Tabela 2. Nasilenie objawów septoriozy paskowanej liści pszenicy i mączniaka prawdziwego zbóż i traw u wybranych linii/odmian Triticum w latach 2016-2017 (procent porażonej powierzchni liści flagowych)

Table 2. Severity of Septoria tritici blotch and powdery mildew on selected Triticum lines/cultivars in 2016-2017 (\% infected area of flag leaves)

\begin{tabular}{|c|c|c|c|c|c|c|}
\hline \multirow[b]{2}{*}{$\begin{array}{l}\text { Gatunek Triticum / numer taksonu lub odmiana } \\
\text { Species Triticum / number of taxon or cultivar }\end{array}$} & \multicolumn{3}{|c|}{ Zymoseptoria tritici } & \multicolumn{3}{|c|}{ Blumeria graminis } \\
\hline & 2016 & 2017 & $\begin{array}{l}\text { średnio } \\
\text { dla linii } \\
\text { average } \\
\text { for lines }\end{array}$ & 2016 & 2017 & $\begin{array}{l}\text { średnio } \\
\text { dla linii } \\
\text { average } \\
\text { for lines }\end{array}$ \\
\hline T. monococcum ssp. monococcum 405 & $0 \mathrm{fg}$ & $0 \mathrm{fg}$ & $0 \mathrm{E}$ & $0 \mathrm{~d}$ & $0 \mathrm{~d}$ & $0 \mathrm{~B}$ \\
\hline T. turgidum ssp. dicoccum 475 & $0,10 \mathrm{f}$ & $46,00 \mathrm{~b}$ & $23,05 \mathrm{~B}$ & $0,80 \mathrm{~d}$ & $0 \mathrm{~d}$ & $0,40 \mathrm{~B}$ \\
\hline T. turgidum ssp. polonicum 618 & $1,00 \mathrm{f}$ & $17,00 \mathrm{c}$ & $9,00 \mathrm{C}$ & $1,00 \mathrm{~d}$ & $0 \mathrm{~d}$ & $0,50 \mathrm{~B}$ \\
\hline T. aestivum ssp. spelta 157 & $0,08 \mathrm{fg}$ & $0 \mathrm{fg}$ & $0,04 \mathrm{E}$ & $0,16 \mathrm{~d}$ & $0 \mathrm{~d}$ & $0,08 \mathrm{~B}$ \\
\hline $\begin{array}{l}\text { T. aestivum ssp. spelta } \\
\text { odmiana - cultivar Wirtas }\end{array}$ & $0,30 \mathrm{f}$ & $11,00 \mathrm{~d}$ & $5,65 \mathrm{CD}$ & $0,40 \mathrm{~d}$ & $0 \mathrm{~d}$ & $0,20 \mathrm{~B}$ \\
\hline T. aestivum ssp. aestivum 307 & $0,60 \mathrm{f}$ & $90,01 \mathrm{a}$ & $45,30 \mathrm{~A}$ & $5,00 \mathrm{~b}$ & $29,00 \mathrm{a}$ & $17,00 \mathrm{~A}$ \\
\hline $\begin{array}{l}\text { T. aestivum ssp. aestivum } \\
\text { odmiana - cultivar Sumai } 3\end{array}$ & $1,00 \mathrm{f}$ & $7,78 \mathrm{de}$ & $4,39 \mathrm{D}$ & $0 \mathrm{~d}$ & $2,33 \mathrm{c}$ & $1,67 \mathrm{~B}$ \\
\hline Średnio w latach - Average in years & $0,31 X$ & $17,10 \mathrm{Y}$ & - & $0,79 X$ & $3,11 \mathrm{Y}$ & - \\
\hline
\end{tabular}

Jednakowymi literami oznaczono wartości nieróżniące się istotnie według testu Newmana-Keulsa $(\mathrm{p}<0,01)$ : a-f - dla interakcji lata $\times$ odmiana/linia; $\mathrm{X}-\mathrm{Y}$ - przeciętnie w latach; A, B - przeciętniedla odmian/linii

Values labeled by the same letter do not differ significantly at Newman-Keuls test $(\mathrm{p}<0.01)$ : $\mathrm{a}-\mathrm{f}-$ for interactions year $\times$ line/cultivar; $\mathrm{X}-\mathrm{Y}-\mathrm{for}$ year; A, B - for line/cultivar

Tabela 3. Nasilenie objawów septoriozy paskowanej liści pszenicy u wybranych linii/odmian Triticum w szklarni (procent porażonej powierzchni liści flagowych)

Table 3. Severity of Septoria blotch on selected Triticum lines/ cultivars in the glasshouse trial (\% infected area of flag leaves)

\begin{tabular}{l|c}
\hline $\begin{array}{l}\text { Gatunek Triticum / numer taksonu lub odmiana } \\
\text { Species Triticum / number of taxon or cultivar }\end{array}$ & $\begin{array}{c}\text { Zymoseptoria } \\
\text { tritici }\end{array}$ \\
\hline T. monococcum ssp. monococcum 405 & $1,67 \mathrm{~b}$ \\
\hline T. turgidum ssp. dicoccum 475 & $2,73 \mathrm{~b}$ \\
\hline T. turgidum ssp. polonicum 618 & $2,07 \mathrm{~b}$ \\
\hline T. aestivum ssp. spelta 157 & $0 \mathrm{~b}$ \\
\hline $\begin{array}{l}\text { T. aestivum ssp. spelta } \\
\text { odmiana - cultivar Wirtas }\end{array}$ & $0 \mathrm{~b}$ \\
\hline T. aestivum ssp. aestivum 307 & $7,00 \mathrm{a}$ \\
\hline $\begin{array}{l}\text { T. aestivum ssp. aestivum } \\
\text { odmiana - cultivar Sumai } 3\end{array}$ & $0,73 \mathrm{~b}$ \\
\hline
\end{tabular}

Jednakowymi literami oznaczono wartości nieróżniące się istotnie według testu Newmana-Keulsa $(\mathrm{p}<0,01)$

Values denoted by the same letter do not differ significantly at Newman-Keuls test $(\mathrm{p}<0.01)$

Tetraploidalne gatunki T. turgidum ssp. polonicum 618 i T. turgidum ssp. dicoccum 475 porażane były przez Z. tritici zarówno w warunkach polowych, jak i w szklarni (tab. 2, 3). Jednak nasilenie objawów chorobowych pojawiających się w postaci wydłużonych nekroz bez piknidiów nie przekra- czało 17\% w przypadku pierwszego gatunku. W roku 2017 nekrozy na liściach flagowych $T$. turgidum ssp. dicoccum 475 obejmowały $46 \%$ powierzchni liści flagowych (tab. 2). W badaniach Somai-Jemmali i wsp. (2017) gatunek T. turgidum ssp. durum inokulowany zawiesiną zarodników Z. tritici wykazywał typowe objawy porażenia z piknidiami, w cytowanych badaniach ich nasilenie sięgało nawet $60 \%$ powierzchni blaszki liścia. Z kolei Seifbarghi i wsp. (2009) obserwowali septoriozę liści na gatunkach T. turgidum ssp. polonicum i T. turgidum ssp. dicoccum.

$\mathrm{W}$ warunkach polowych na zielonych liściach diploidalnego gatunku T. monococum spp. monococum 405 nie odnotowano objawów septoriozy paskowanej. W szklarni, w ciągu 30 dni obserwacji po inokulacji liści, zaobserwowano małe nekrotyczne plamki na kilku liściach. Nie stwierdzono jednak obecności piknidiów. Jing i wsp. (2008) badający interakcje między kilkoma izolatami $Z$. tritici i genotypami T. monococcum spp. monococum wyróżnili kilka fenotypów odporności roślin. Pierwszy charakteryzował się wytwarzaniem plam i piknidiów. Drugi wyróżnił się tworzeniem niedojrzewających piknidiów, bez zarodników. Trzeci typ fenotypowej odporności charakteryzował się brakiem rozwoju piknidiów, także wzrost grzyba był zahamowany w aparacie szparkowym, co objawiało się jego czernieniem (Jing i wsp. 2008).

W warunkach polowych, praktycznie wszystkie testowane pszenice, z wyjątkiem T. monococcum spp. monococcum, 
porażane były przez B. graminis (tab. 2). Na liściach obserwowano objawy typowe dla mączniaka prawdziwego zbóż i traw. Linia T. aestivum ssp. aestivum 307 była najbardziej podatna na porażenie przez B. graminis. Nasilenie objawów mączniaka prawdziwego na liściach pozostałych badanych pszenic było istotnie mniejsze. W literaturze symptomy tej choroby opisywane są na pszenicach o różnych stopniach ploidalności (Esmail i Draz 2017). Co ciekawe w badaniach filogenetycznych prowadzonych przez Menardo i Wicker (2017) stwierdzono, że izolaty B. graminis f. sp. tritici grupują się w dwóch kladach określonych przez autorów jako Bgt 1 (żywiciel T. aestivum spp. aestivum) i Bgt 2 (żywiciel T. turgidum ssp. dicoccum).

\section{Wnioski / Conclusions}

1. Heksaploidalna linia T. aestivum ssp. aestivum była najbardziej podatna na porażenie przez patogeny $Z$. tritici i B. graminis f. sp. tritici. Podatność heksaploidalnego orkiszu i pszenicy zwyczajnej odmiany Sumai 3 oszacowano na niskim poziomie.

2. Tetraploidale gatunki $T$. turgidum ssp. polonicum i T. turgidum ssp. dicoccum wykazywały przeciętną podatność na porażenie przez patogena $Z$. tritici oraz znikomą na $B$. graminis f. sp. tritici.

3. Diploidalna linia T. monococcum ssp. monococcum nie była porażana przez żaden z omawianych patogenów w warunkach naturalnych, natomiast uległa porażeniu przez Z. tritici po inokulacji roślin w szklarni.

\section{Literatura / References}

Bulletin EPPO 1998. Guideline for the efficacy evaluation of fungicides. PP/1/26/3. Foliar diseases of cereals 28: 279-290.

COBORU 2015. www.coboru.pl/Polska/Wydarzenia/2015/20150119.aspx [dostęp: 22.05.2018].

Esmail S.M., Draz I.S. 2017. Fungal morphogenesis tracking of Blumeria graminis f. sp. tritici on leaf freed of epicuticular wax using scanning electron microscopy. International Journal of Microbiology and Biotechnology 2 (4): 181-188. DOI: 10.11648/j. ijmb.20170204.16.

Jing H.C., Lovell D., Gutteridge R., Jenk D., Kornyukhin D., Mitrofanova O.P., Kema G.H.J., Hammond-Kosack K.E. 2008. Phenotypic and genetic analysis of the Triticum monococcum - Mycosphaerella graminicola interaction. New Phytologist 179 (4): $1121-1132$. DOI: $10.1111 /$ j.1469-8137.2008.02526.x.

Meier U. 2003. Phenological growth stages. p. 269-283. In: "Phenology: An Integrative Science” (M.D. Schwarz, ed.). Kluwer Academic Publishers, Dordrecht/Boston/London.

Menardo F., Wicker T., Keller B. 2017. Reconstructing the evolutionary history of powdery mildew lineages (Blumeria graminis) at different evolutionary time scales with NGS data. Genome Biology and Evolution 9 (2): 446-456. DOI: 10.1093/gbe/evx008.

Mirzwa-Mróz E., Tvaružek L., Zamorski C., Nowicki B. 2005. Research on the development of Mycosphaerella graminicola (Fuckel) Schroeter teleomorph on wheat leaves from Poland and Czech Republic. [Badania rozwoju teleomorfy grzyba Mycosphaerella graminicola (Fuckel) Schroeter na liściach pszenicy z Polski i Czech]. Acta Agrobotanica 58 (1): 59-65. DOI: 10.5586/aa.2005.009.

Mirzwa-Mróz E., Zamorski C. 2002. Podatność genotypow pszenicy ozimej na porażenie przez Mycosphaerella graminicola (Fuckel) Schroeter. [Reaction of winter wheat genotypes to infection by Mycosphaerella graminicola (Fuckel) Schroeter]. Acta Agrobotanica 55 (1): 233-246. DOI: 10.5586/aa.2002.022.

NCBI 2016. National Center for Biotechnology Information, BLAST (Basic Local Alignment Search Tool). http://www.ncbi.nlm.nih. gov/ genbank/ [Accessed: 22.05.2018].

Seifbarghi S., Razavi M., Aminian H., Zare R., Etebarian H.-R. 2009. Studies on the host range of Septoria species on cereals and some wild grasses in Iran. Phytopathologia Mediterranea 48 (3): 422-429. DOI: http://dx.doi.org/10.14601/Phytopathol Mediterr-2940.

Shetty N.P., Jensen J.D., Knudsen A., Finnie C., Geshi N., Blennow A., Collinge D.B., Jørgensen H.J.L. 2009. Effects of $\beta$-1,3-glucan from Septoria tritici on structural defense responses in wheat. Journal of Experimental Botany 60 (15): 4287-4300. DOI: 10.1093/ jxb/erp269.

Simon M.R., Khlestkina E.K., Castillo N.S., Börner A. 2010. Mapping quantitative resistance to septoria tritici blotch in spelt wheat. European Journal of Plant Pathology 128 (3): 317-324. DOI: 10.1007/s10658-010-9640-y.

Somai-Jemmali L., Randoux B., Siah A., Magnin-Robert M., Halama P., Reignault P., Hamada W. 2017. Similar infection process and induced defense patterns during compatible interactions between Zymoseptoria tritici and both bread and durum wheat species. European Journal of Plant Pathology 147 (4): 787-801. DOI: 10.1007/s10658-016-1043-2.

Wachowska U., Konopka I., Duba A., Goriewa K., Wiwart M. 2018. The effects of various plant protection methods on the development of Zymoseptoria tritici and Cephalosporium gramineum, grain yield and protein profile. International Journal of Pest Management. DOI: $10.1080 / 09670874.2018 .1474282$.

White T.J., Bruns T., Lee S., Taylor J. 1990. Amplification and direct sequencing of fungal ribosomal RNA genes for phylogenetics. p. 315-322. In: "PCR Protocols: a Guide to Methods and Applications" (M.A. Innis, D.H. Gelfand, J.J. Sninsky, T.J. White, eds.). Academic Press, San Diego, California, USA. DOI: 10.1016/B978-0-12-372180-8.50042-1.

Wiwart M., Suchowilska E., Kandler W., Sulyok M., Wachowska U., Krska R. 2016. The response of selected Triticum spp. genotypes with different ploidy levels to head blight caused by Fusarium culmorum (W.G.Smith) Sacc. Toxins 8 (4): 112. DOI: 10.3390/toxins8040112. 